\title{
Modelled estimates of spatial variability of iron stress in the Atlantic sector of the Southern Ocean
}

Thomas J. Ryan-Keogh ${ }^{1,2}$, Sandy J. Thomalla ${ }^{1}$, Thato N. Mtshali ${ }^{1}$, Hazel Little ${ }^{2}$

Supplementary Information
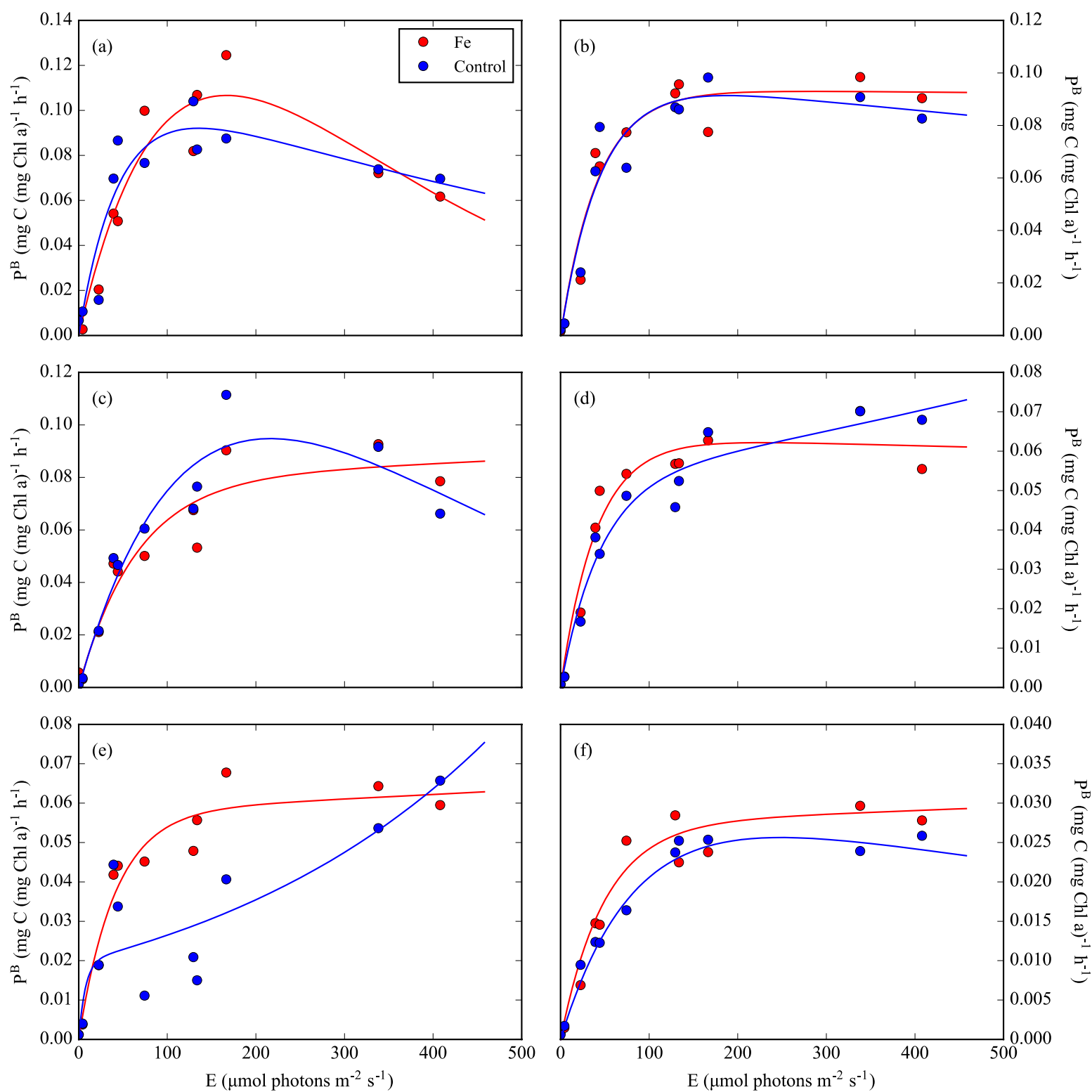

Figure S1: PE curves of productivity $\left(\mathrm{mg} \mathrm{C}\left(\mathrm{mg} \mathrm{Chl} \mathrm{a}^{-1} \mathrm{~h}^{-1}\right)\right.$ with $(\mathrm{Fe}$, red dots) and without (Control, blue dots) the addition of iron for experiments (a) 1, (b) 2, (c) 3, (d) 4, (e) 5 and (f) 6; lines represent a non-linear least squares fit to the equation of Platt et al. (1980). 
Figure S2
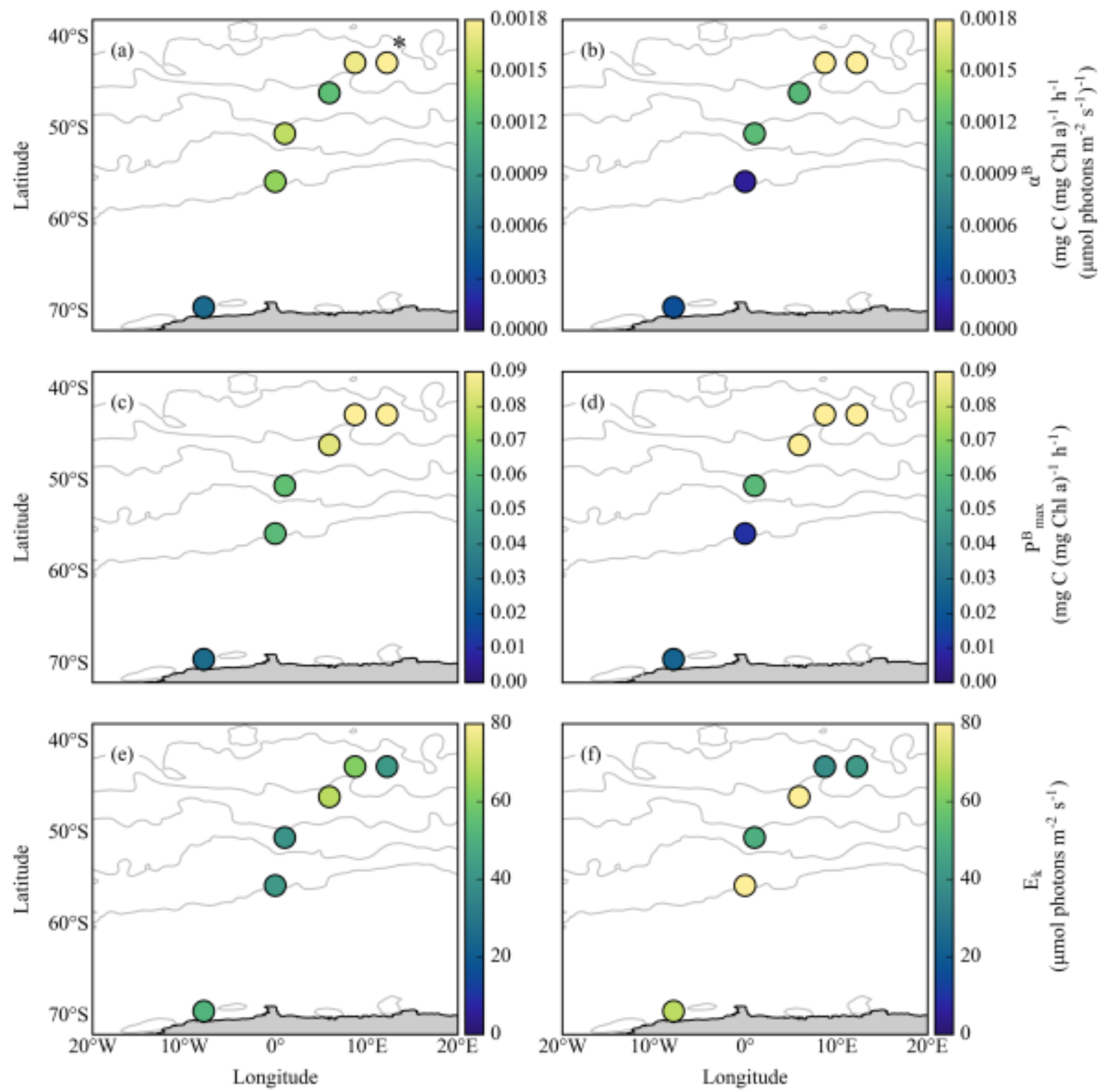

Figure S2: PE parameters (a) $\alpha^{\mathbf{B}}\left(\mathrm{mg} \mathrm{C}(\mathrm{mg} \mathrm{Chl} \mathrm{a})^{-1} h^{-1}\left(\mu \mathrm{mol} \text { photons } \mathrm{m}^{-2} \mathrm{~s}^{-1}\right)^{-1}\right)$, (b) $\mathbf{P}^{\mathrm{B}}{ }_{\max }\left(\mathrm{mg} \mathrm{C}(\mathrm{mg} \mathrm{Chl} \mathrm{a})^{-1} \mathrm{~h}^{-1}\right)$ and (c) $E_{k}\left(\mu \mathrm{mol}\right.$ photons $\left.\mathrm{m}^{-2} \mathrm{~s}^{-1}\right)$ for the iron addition and control treatments of experiments set up in the Atlantic sector of the Southern Ocean. 


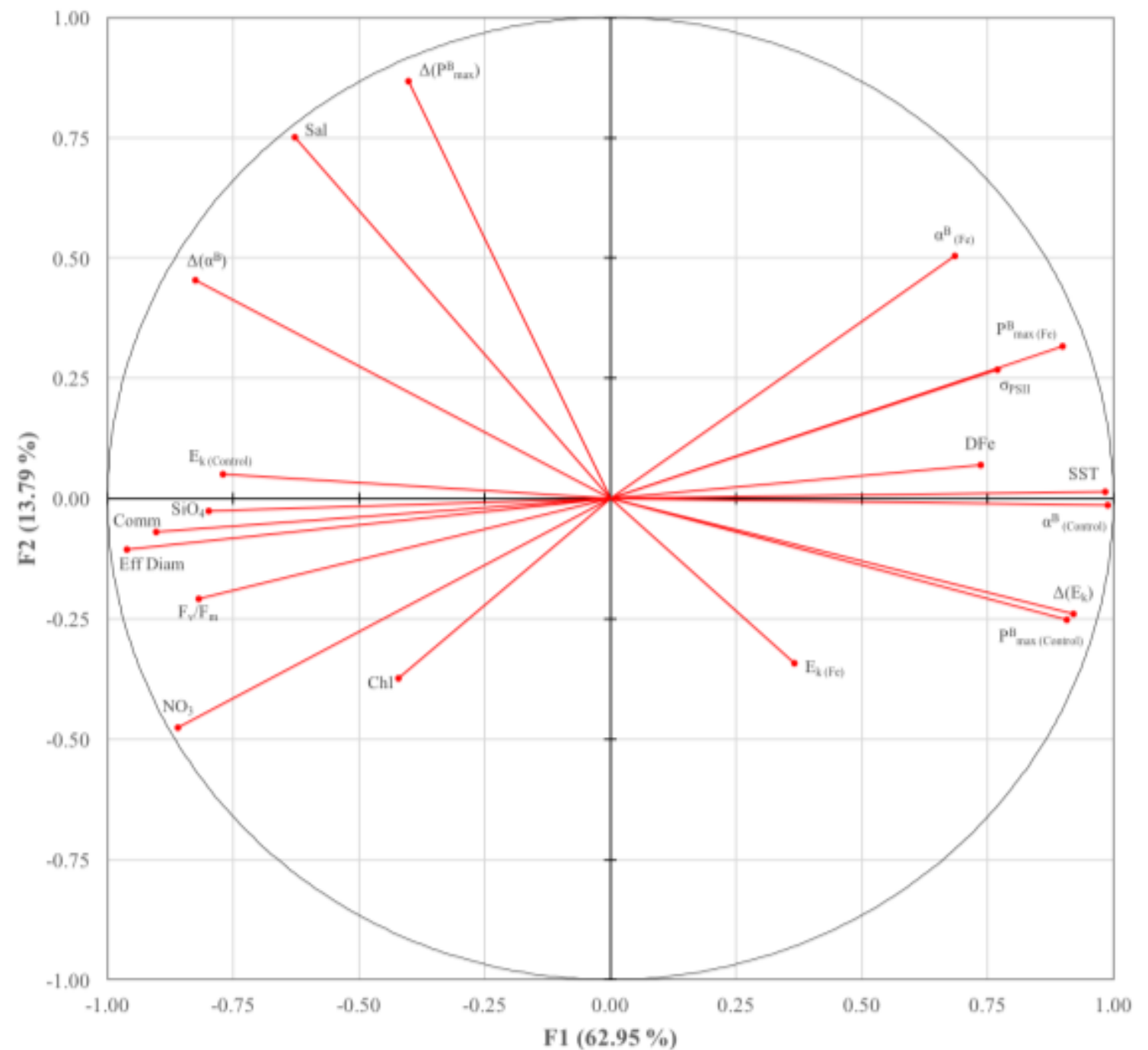

Figure S3: PCA: projection of the photosynthetic parameters determined experimentally and in situ variables measured, including: $\alpha^{\mathrm{B}}, \mathrm{P}_{\text {max }}^{\mathrm{B}}$ and $\mathrm{E}_{\mathrm{k}}$ from the both $\mathrm{Fe}$ and control treatments, the relative differences, sea surface temperature (SST), Salinity, Nitrate, Silicate and dissolved Iron concentration, Chl concentration, Effective Diameter, $\mathbf{F}_{\mathrm{v}} / \mathrm{F}_{\mathrm{m}}, \sigma_{\mathrm{PSII}}$ and Community composition (ratio of Diatoms to Haptophytes). 

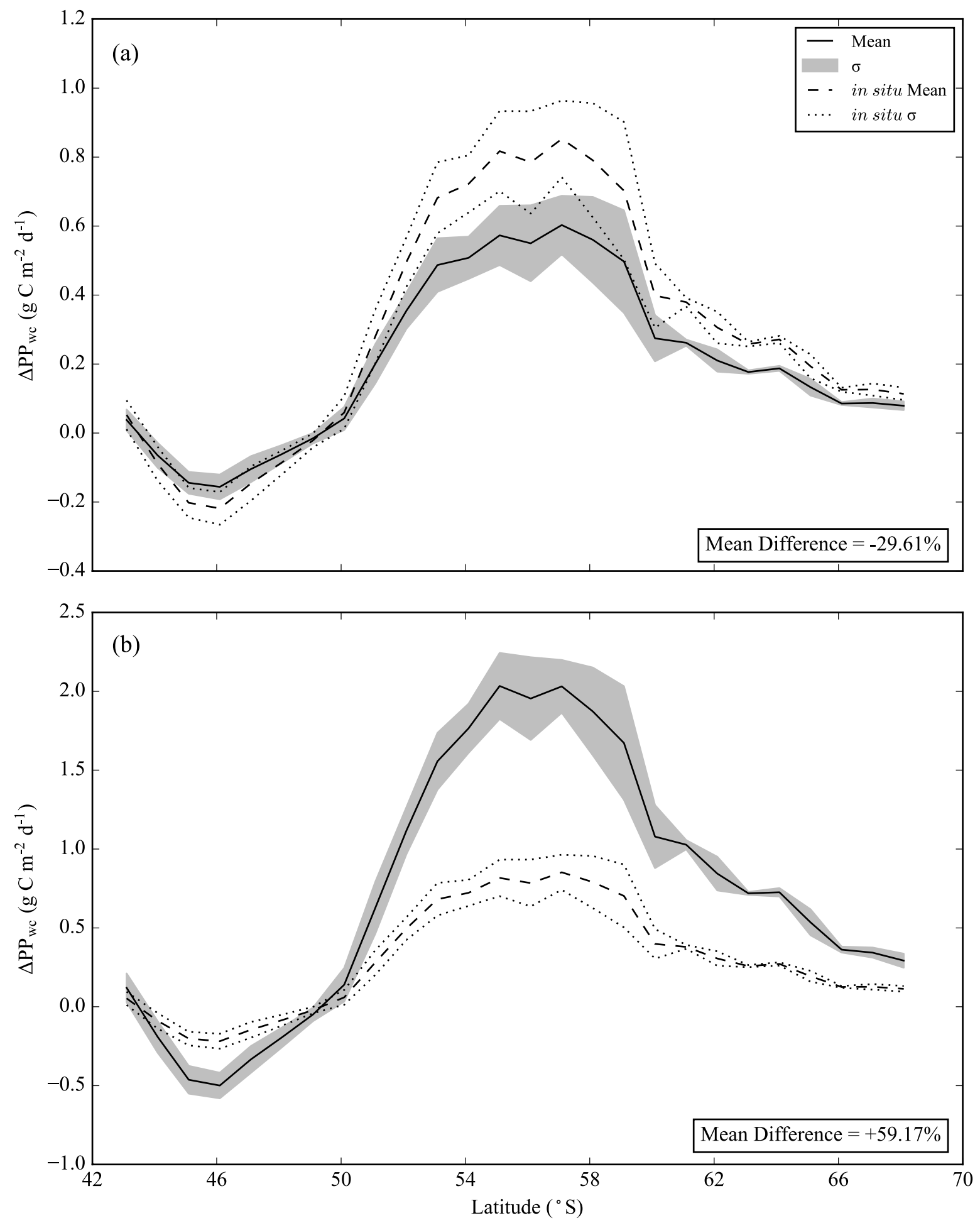

Figure S4: The absolute mean differences in depth integrated primary production $\left(\Delta P P_{w c}\right)$ with \pm standard deviation $(\sigma)$ interpolated along the transect line utilizing the (a) increased $K_{d}$ values and (b) decreased $K_{d}$ values; also displayed is $\mathbf{P P} \mathbf{P}_{\mathrm{wc}}$ derived utilizing in situ $\mathbf{K}_{\mathrm{d}}$. 

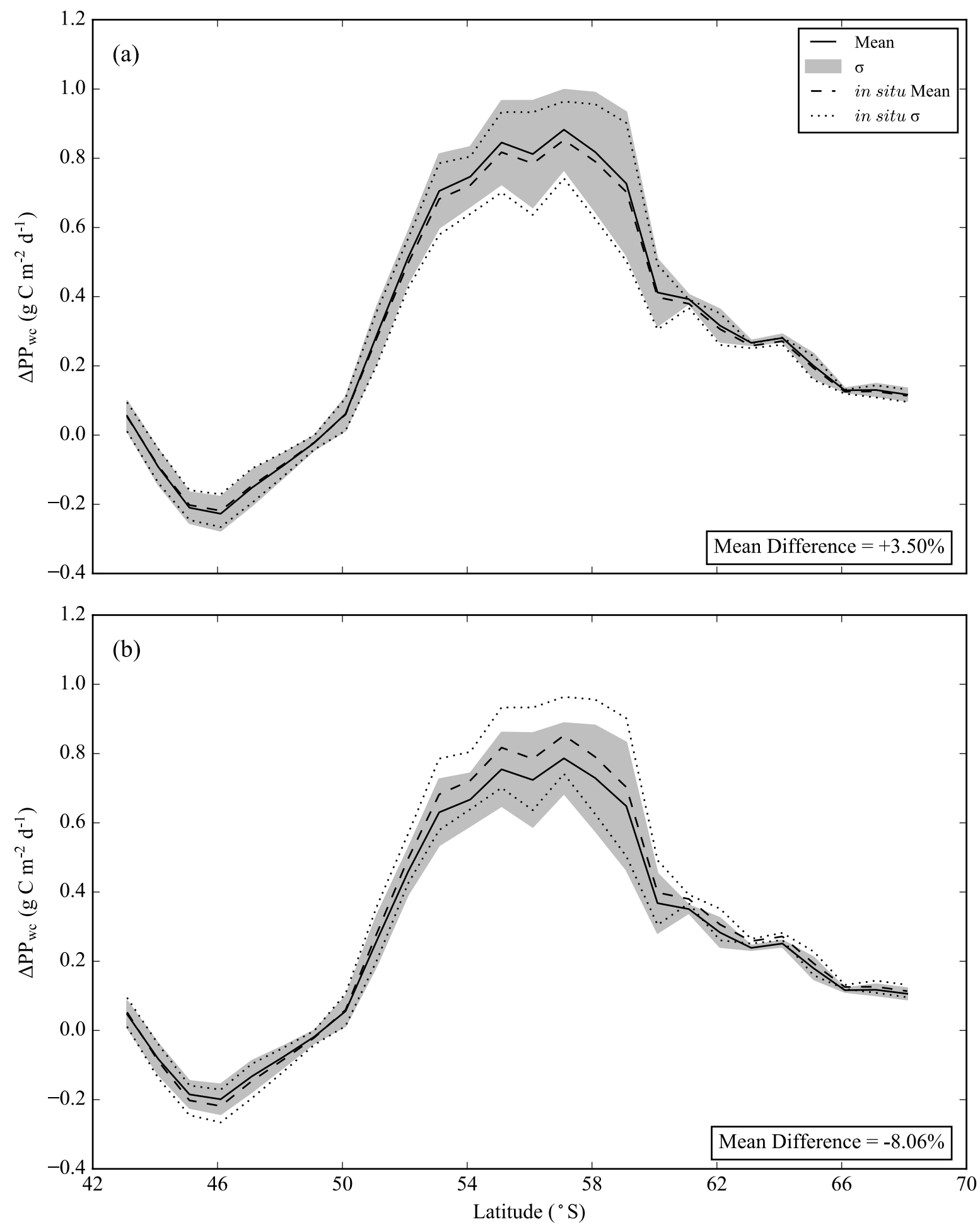

Figure S5: The absolute mean differences in depth integrated primary production $\left(\triangle P P_{w c}\right)$ with \pm standard deviation (б) interpolated along the transect line utilizing the (a) increased PAR values and (b) decreased PAR values; also displayed is $\mathbf{P P} \mathbf{w c}_{\mathrm{wc}}$ derived utilizing in situ PAR. 

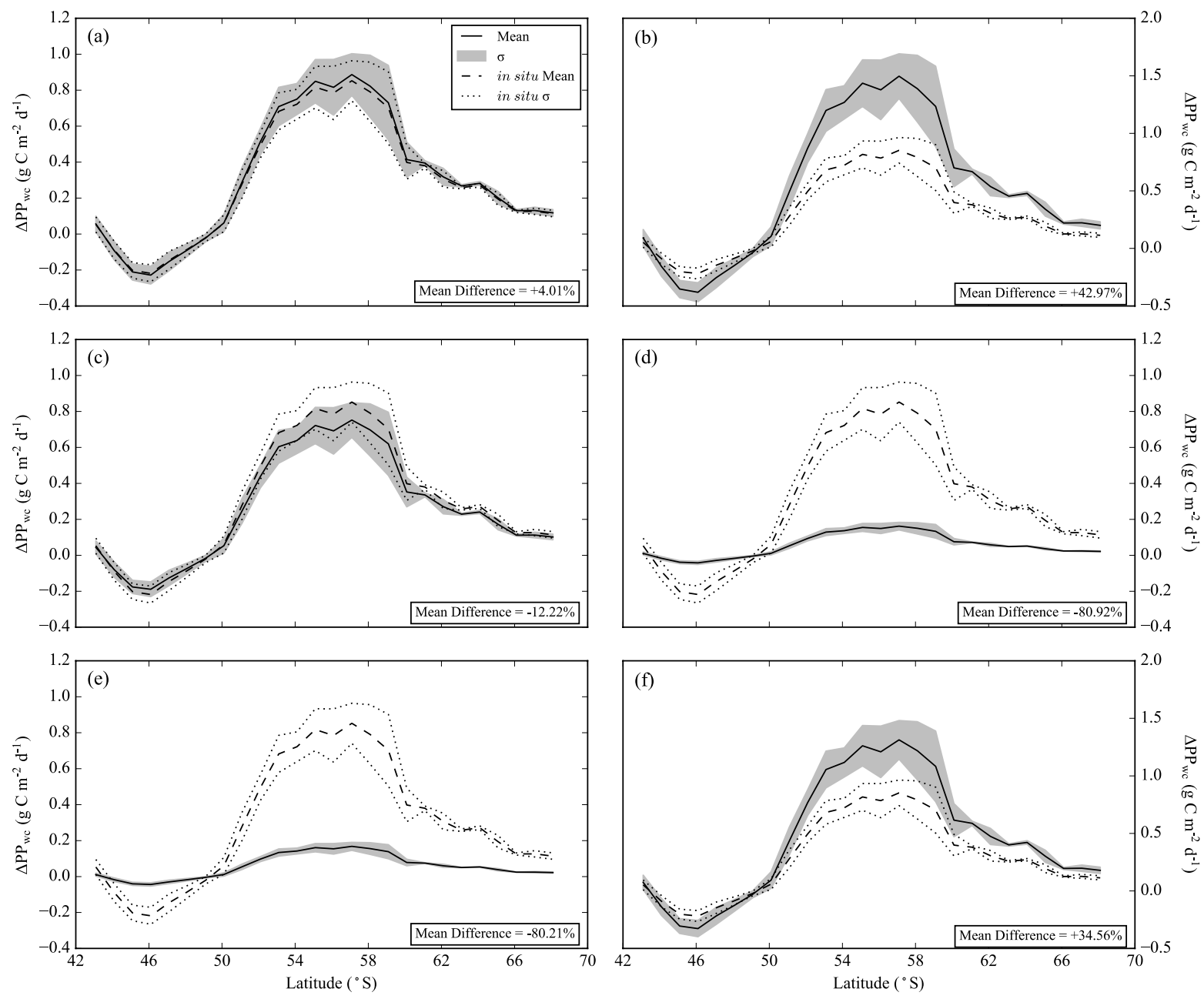

Figure S6: The absolute mean differences in depth integrated primary production $\left(\triangle P P_{w c}\right)$ with \pm standard deviation ( $\sigma$ ) interpolated along the transect line utilizing increased (a) $\alpha$ values and (b) $P_{\max }$ values, decreased (c) $\alpha$ values and (d) $P_{\max }$ values, (e) increase $\alpha$ and decreased $P_{\max }$ values and (f) decreased $\alpha$ and increased $P_{\max }$ values. Displayed on all plots is the $\mathbf{P} \mathbf{P}_{\mathrm{wc}}$ derived utilizing the in situ $\alpha$ and $\mathbf{P}_{\max }$ values. (Please note the different scales in subplots $b \& \mathbf{f}$ ). 